\title{
PEMANTAUAN GUNUNG TANGGAMUS BERSAMA ANGGOTA KOPASUS TNI-AD
}

\author{
Andreas Andoyo1, Riki Renaldo ${ }^{2}$ \\ 1LP3K Lampung, Pringsewu, Lampung \\ 1J1. SD N Fajar Agung, Kel. Fajar Risuk, Pringsewu, Lampung, Indonesia \\ 1,2Program Studi Sistem Informasi, STMIK Pringsewu, Lampung \\ 1,2J1. Wisma Rini No.09 Pringsewu, Lampung, Indonesia \\ E-Mail : aandoyo@gmail.com
}

\begin{abstract}
Climbing activities carried out by the Army Special Forces Kopasus team in collaboration with STMIK Pringsewu and the community on the slopes of Mount Tanggamus provide learning values for young people, the community about the importance of preserving nature in order to stay sustainable and protecting the ecosystem in it. This activity which involves students and the community provides information on how humans need nature as energy and food resources. Besides that, understanding insights on nature preservation for the community will have an impact on the preservation of nature in the Tanggamus Regency.
\end{abstract}

Keywords: Mountain, Tanggamus, community, TNI

\section{PENDAHULUAN}

\subsection{Latar Belakang Kegiatan}

Indonesia sebagai salah satu negara kepulauaan yang memiliki berbagai kekayaan hasil alam baik berupa pertanian, perikanan, pertambangan dan terlebih lagi di sector kehutanan yang mana indonesia merupakan salah satu paru-paru dunia. (KementrianPUPR 2014) Ada satu tempat di Provisnsi Lampung Khususnya di Kabupaten Tanggamus yang memiliki daya tarik yaitu Gunung Tanggamus yang menjadi favorit para pendaki. Tempat itu dinamai basecamp sonokeling. Basacamp ini berada pada ketinggian 700 meter di atas permukaan laut. Basecamp ini berada di kawasan hutan sonokeling, pepohonan yang ditanam Dinas Kehutanan Provinsi Lampung 45 tahun lalu. Di sini para pendaki biasa menggelar perkemahan. Tempat ini berada kurang lebih 2 jam perjalanan mendaki. Pas betul sebagai tempat beristirahat setelah lelah mendaki punggung gunung dengan kemiringan 45 derajat itu. Dengan adanya Gunung tanggamus yang merupakan salah satu pegunungan aktif di Provinsi Lampung dan sering di jadikan tempat 
pendakian makanya sering diadakan patroli rutin untuk pemantoaan agar para pendaki aman.

(Muhaimin, Lailaty, dan Hidayat 2018) Kaki Gunung Tanggamus berdiri kokoh di antara tiga kecamatan, yakni Kotaagung, Gisting, dan Ulubelu. (BPSTanggamus 2018) Di punggung gunung yang berada di Kecamatan Ulubelum tersimpan sumber energy panas bumi yang belum dikelola. Namun, secara umum punggung gunung yang dikelilingi desa-desa dari tiga kecamatan tersebut, sudah menjadi kebun kopi rakyat. Pohon-pohon besar sudah lama hilang lantaran ditebang dan digantikan tanaman kopi.

Gunung ini sangat eksotis. Puncaknya yang selalu ditutupi kabut menyimpan sesuatu yang tak dimiliki gunung lain, yakni hutan lumut. Hutan lumut menjadi daya tarik tersendiri bagi para pendaki. Dari kalangan para pendaki ada ungkapan "kalau belum sampai di hutan lumut berarti belum sampai ke Tanggamus". Ungkapan yang tidak berlebihan karena hutan lumut berada tepat di puncaknya.

\subsection{Indentifikasi Masalah}

Pengabdianini dinilai sangat pelu dilaksanakan mengingat masih minimnya masyarakat yang peduli dengan kelestarian alam di sekitar Gunung Tanggamus. Beberapa masalah yang dapat kami rinci adalah sebagai berikut:

1. Latar belakang pendidikan yang rendah

2. Pengalaman dalam melestarikan kawasan pegunungan

3. Tenaga ahli atau spesialisasi dibidang Giologi dan pelestarian kawasan pegunungan di Kabupaten Tanggamus yang kurang.

\section{TUJUAN DAN MANFAAT}

\subsection{Tujuan Kegiatan}

STMIK Pringsewu adalah suatu lembaga pendidikan yang bekonsentrasi dalam bidang teknologi dan informasi. Sudah selayaknya kita memberikan "arti" keberadaan kita ditengah masyarakat sebagi lembaga yang mampu mejaga bahka memeberdayakan inforamsi yang bermanfaat di Propinsi Lampung. Kegaitan ini bertujuan untuk menyedikana suatu informasi kepada masyarakat tentang 
pentingnya menjaga kelestarian ligkungan dan alam sekitar untuk masadepan yang lebih baik.

\subsection{Manfaat Kegiatan}

Manfaat yang ingin dicapai dalam pemantauaan gunung tanggamus adalah bagaimana sedini mungkin mencegah kerusakan alam di sekiatar gunung tanggamus akibat ulah masyarakat yang tidak bertanggung jawab dan pemamantauaan keaktifan gunung tanggamus untuk mencegah hal-hal yang tidak di inginkan yang berasal dari aktifitas fulkanik di Gunung Tanggamus.

\section{METODE PELAKSANAAN}

\subsection{Sasaran Kegiatan}

Sasaran dari Pemantauaan Gunung Tanggamus ini adalah difokuskan pada peningkatan kesadaran masyarakat tentang pentingnya menjaga kelestariaan lingkungan dan alam sekitarnya.

\subsection{Jadwal Kegiatan}

Kegiatan ini dilaksanakan dengan sebelumnya diadakan persiapan materi dan kegiatan selama 1 hari kemudian dilanjutkan kegiatan pendakian dan pemantauan selama 2 hari yaitu tanggal 20 Mei 2011 sampai dengan 21 Mei 2011, dan terakhir adalah evaluasi dan pelaporan kegiatan.

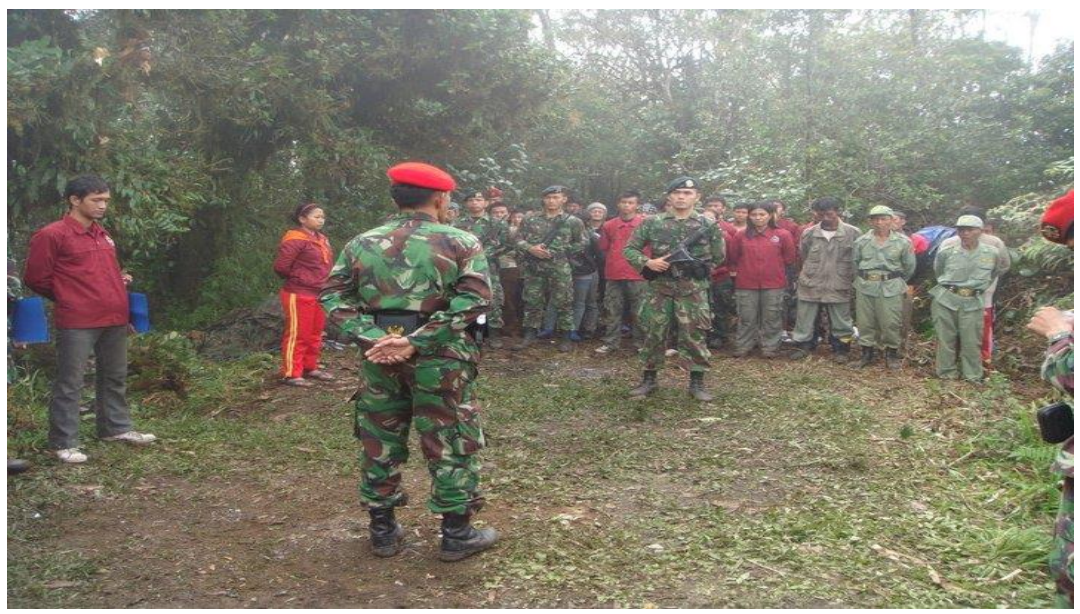




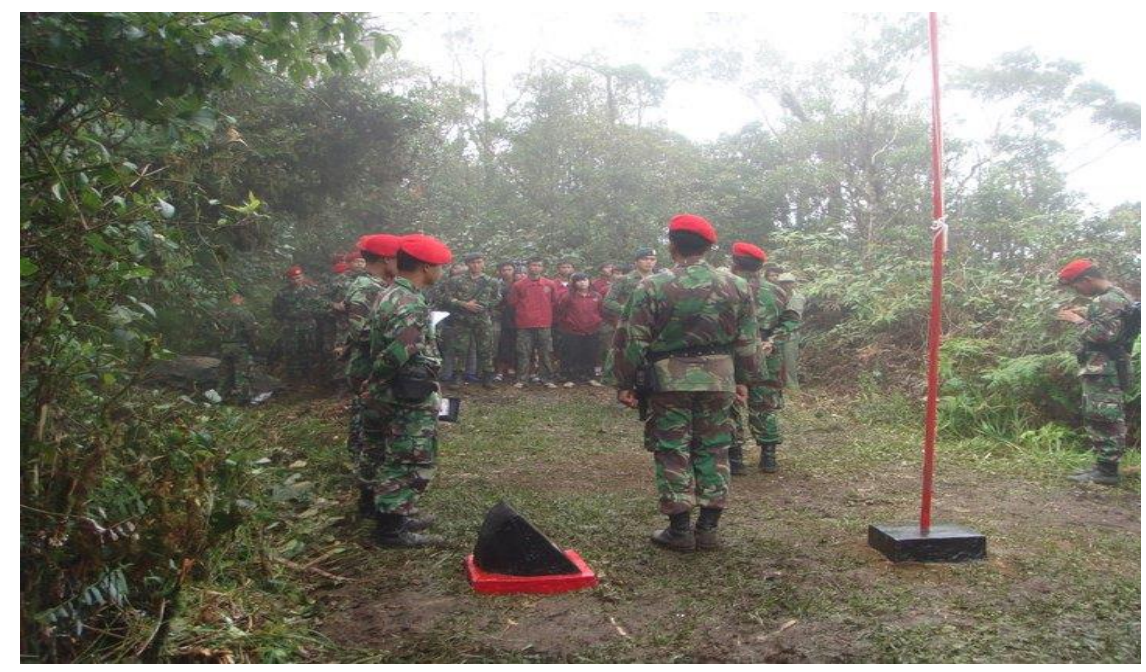

Gambar 1. Foto apel kegiatan di puncak Gunung Tanggamus

\section{KESIMPULAN}

Kegiatan ini dapat dikatakan berhasil dengan baik, hal ini dapat dibuktikan dengan sikap antusias peserta dalam mengikuti kegiatan ini. Antusias tersebut dilanjutkan dengan peran aktif para anggota dan masyarakat yang mengikuti pendakian. Hasil kegiatan ini juga dapat dilihat dari banyaknya kegiatan masyarakat yang melakukan pendakian guna melesatrikan lingkungan dan alam di wilayah kabupaten tanggamus.

\section{DAFTAR PUSTAKA}

BPSTanggamus. 2018. Statistik Daerah Kabupaten Tanggamus 2018. Rosaffinah. Tanggamus: https:/ / tanggamuskab.bps.go.id.

KementrianPUPR. 2014. “BAB 2 Profil Kabupaten.” Hal. 1-29 in Prpfil Kabupaten. Muhaimin, Muhamad, Intani Quarta Lailaty, dan Imawan Wahyu Hidayat. 2018.

“Keragaman tumbuhan di kawasan Hutan Lindung Gunung Tanggamus , Lampung dan upaya konservasinya (Plants diversity in Mount Tanggamus Protected Forest, Lampung and its conservation efforts)." Hal.144-50 in PROS SEM NAS MASY BIODIV INDON 4. Vol. 4. 